\title{
Observation of the embolus protection filter for carotid artery stenting
}

Kentaro Hayashi M.D., ${ }^{1}$ Naoki Kitagawa M.D., ${ }^{1}$ Minoru Morikawa M.D., ${ }^{2}$ Takeshi Hiu M.D., ${ }^{1}$ Yoichi Morofuji M.D., ${ }^{1}$ Kazuhiko Suyama M.D., ${ }^{1}$ Izumi Nagata M.D. ${ }^{1}$

${ }^{1}$ Department of Neurosurgery, Nagasaki University School of Medicine, Nagasaki, Japan

${ }^{2}$ Department of Radiology, Nagasaki University School of Medicine, Nagasaki, Japan

Correspondence to Kentaro Hayashi M.D.

1-7-1 Sakamoto, Nagasaki-city 852-8501 Japan

Tel; +81-95-819-7375

Fax; +81-95-819-7378

e-mail; kenkuni@net.nagasaki-u.ac.jp 


\begin{abstract}
Background: Carotid artery stenting (CAS) in high-surgical-risk patients is considered as an effective alternative to carotid endarterectomy. Since the occurrence of distal embolization with CAS is still major concern, embolus protection device is usually employed during the procedure. We developed a technique for observation of embolus protection filter and evaluate the debris or thrombus microscopically, and the pathological findings were compared with preoperative imaging studies.

Patients and Methods: After completing CAS, filter membrane was stained with hematoxylin \& eosin (HE) solution and removed from filer strut. Mounting onto a glass slide, filter was evaluated under microscope. Plaque debris and appearance of filter membrane were evaluated and the covered area was measured. The pathological findings were compared with preoperative imaging studies.
\end{abstract}

Results: Microscopical observation of the slide revealed atheromatous debris as well as thrombotic material to the filter membrane. HE stain facilitates the characterization of the debris composition, namely thrombotic debris, calicified debris, organized debris, fibrous debris, lipid-rich debris. The subtypes of debris were consistent with preoperative imaging studies. Thus. in cases of intraprocedural flow impairment, more than $50 \%$ of filter area was covered with debris or thrombotic material.

Conclusion: Carotid plaque debris captured during carotid stenting with protection filter can be visualized with HE stain on the glass side. This simple method allows us to better understand plaque debris and appearance of embolus protection filter. 
Key word: carotid plaque, stent, microscopical observation, hematoxylin-eosin stain 


\section{Introduction}

Percutaneous endovascular intervention is a well-accepted treatment for atherosclerotic stenosis of carotid arteries. Distal embolism is always a feared complication during endovascular procedures in carotid arteries $(2,10,16)$. This high propensity for embolic plaque debris led to the development of distal protection techniques to be used during endovascular procedures performed for lesions of the carotid bifurcation $(12,13,15)$.

We have ever reported a debris observation technique for aspirated blood sample from carotid artery stenting (CAS) using occlusion balloon system (5). Here we modified this technique for filter-protected CAS and evaluated the quality of debris and appearance of embolus protection filter comparing with preoperative imaging studies.

\section{Patients and Methods}

Carotid artery stenting was performed for patient with high-grade internal carotid artery stenosis. The anticoagulant and antithrombotic protocol comprised administration of $200 \mathrm{mg}$ of aspirin and $75 \mathrm{mg}$ of clopidogrel at least 3 days before the procedure. Intra-arterial heparin bolus at the beginning of the procedure (70-100 IU/kg body weight) maintained an activated coagulation time of $300 \mathrm{~s}$. All procedure were performed via the femoral approach using an 8 Fr guiding catheter. Angioguard embolus protection filter (Cordis Corporation, Miami Lakes, FL, USA) was employed to prevent 
distal embolism during stenting. Following predilation, Precise self-expandable stent (Cordis Corporation) was positioned covering stenotic portion and deployed. After stent deployment, postdilation was performed with a balloon matched to the distal reference vessel diameter in order to achieve optimal stenting result (nominal balloon diameter 5 $\mathrm{mm}$, inflation pressure 12-14 atm). Completing the procedure, filter device was retrieved with capture sheath. Then, the filter membrane was submitted for analysis. Ten samples were processed without difficulty.

Larger piece of debris were visible by the naked eye. After brief washing with distilled water, the filter was placed Mayer's hematoxylin solution for 1 minutes, and then placed in eosin for another 1 minute with brief wash in between procedures (Fig. 1A). Subsequently, the filter membrane was cut off from the strut and mounted onto a glass slide using paramount (Fig. 1B). Finally, the hematoxylin \& eosin (HE)-stained debris on the filter could be visualized using light microscopy. The subtype of debris was classified and the area covered with plaque debris or thrombotic material was measured with NIH image.

Preoperatively, the stenotic lesion was evaluated with ultrasonography, CT angiography and high-resolution MRI. The calcification level of the plaque was graded no $(-)$, minor $(+)$, moderate $(++)$ and severe $(+++)$. For the T1 weighted two-dimentional fast-spin echo, the TR/TE was 800/11 ms and the echo train length was 4. Fat suppression was used and the in-plane resolution was $0.5 \mathrm{~mm}$. Assessments were made by an independent observer in a blinded fashion. Postoperatively, the results of imaging studies were compared with pathological findings. 


\section{Results}

Case description and debris subtype

A 80-year-old man (Case 9) who had a history of hypertension and hypercholesterolemia presented our hospital because of left amourosis fugax. Angiography showed high-grade stenosis at the origin of the left internal carotid artery (ICA; Fig. 2A). The stenotic lesion was demonstrated as high-density lesion with CT angiography and was graded as severe calcification (Fig. 2B). High-resolution MRI showed isointensity plaque, indicating stable plaque (Fig. 2C). CAS was performed for the left ICA stenosis using embolus protection filter. Self-expandable stent was placed into the left ICA following predilation (Fig. 2D). Intraprocedural angiography showed impairment of blood flow i.e. slow flow phenomenon. The debris containing blood stasis was removed with aspiration catheter and the flow was restarted retrieving the filter. Postoprocedural control angiography showed excellent widening of the stenosis (Fig. 2E). The filter membrane was examined and the covered area was measured as 63.7\% (Fig. 2F). Hypermagnification of the debris demonstrated irregular hard debris categorized as organized debris (Fig. 2G). Thus, hypermagnification of the filter membrane showed thrombotic material to the pore or numerous cells adhesion to the membrane (Fig. 2H).

In case 7, ultrasonography showed hypoechoic lesion and high-resolution MRI showed hyperintensity plaque, which indicated vulnerable lesion, and greater 
abundance of lipid-rich debris, which was soft and yellowish, was revealed on the embolus protection filter (Fig. 3A). Postoperative diffusion weighted MRI showed multiple hyperintensity lesion, indicating shower embolism. In radiation induced stenosis, high resolution MRI showed isointesity lesion, which indicated stable plaque. Under microscope, fusiform cells with fibrous tissue were identified in the debris and was categorized as fibrous debris (Case 5; Fig. 3B). Calcified debris, which was hard and stained with hematoxylin, was dominant in the material from hyperechoic lesion (Fig. 3C). And thrombotic debris stained with eosin was seen in the heterogeneous echoic lesion (Fig. 3D).

The patient characteristics and preoperative imaging study were listed in Table 1 and the results of debris analysis were listed in Table 2. The results of debris observation appeared to be consistent with preoperative imaging studies. The area covered with plaque debris or thrombotic material was $43.5 \%$ (mean [range $18.5 \%$ to 88.5\%]). The blood flow was impaired intraoperatively in four cases and $88.5 \%$ of filter area was covered in case of no-flow. In three cases of slow-flow phenomenon, more than $50 \%$ of area was covered. Finally, this debris observation technique required neither specific instrumentation nor equipment and the slides were suitable for long-term storage.

\section{Discussion}


Recently, CAS has been introduced as an alternative revascularization modality for patients with symptomatic or asymptomatic high-degree stenosis in the extracranial carotid arteries. Several randomized studies and registries have shown similar outcomes when compared with carotid endarterectomy in high-risk populations $(17,18)$. Emboli are known to be associated with a high neurological complication rate and are also recognized as a potential cause of periprocedural stroke during CAS. Currently, to avoid embolization, the distal trapping technique using balloon or filter device has been developed $(12,13,15)$.

Regarding with debris analysis, Rogers et al. (14) and Hill et al. (7) reported the volume and sized of particulate debris which were retrieved during saphenous vein graft stenting or CAS. They analyzed debris using microparticle analyzer and found that most particle were $<100 \mu \mathrm{m}$. Only a few studies give a detailed morphological evaluation of the material retrieved during percutaneous procedure. Angelini et al. (1) reported collection and histopathologic analysis of carotid debris from CAS. They showed scanning electron micrographic image and cross section of the filter membrane, identifying necrotic material, calcium precipitate, cholesterol clefts, fibrotic tissue fragments and evidence of platelet. Maleux et al. (11) collected debris with centrifugation and embedded into paraffin. And they observed the section of debris precipitate with HE stain. Although they revealed significant findings of plaque debris, their technique required special instruments or equipment, and appeared not to be standard technique for debris analysis. 
We have ever reported a debris observation technique for blood sample from CAS with guardwire system and modified this technique for embolus protection filter in this research. After HE staining, the filter membrane was cut off from strut and mounted on a glass slide for microscopical observation. The time required for performing the procedure is short, taking only 30 minutes, and was economical. Furthermore, no special tool was needed. Morphological analysis of embolized material proved debris dislocated during the percutaneous intervention from atheromatous plaques. Thus, we have identified the composition of captured material to be organized debris (Fig. 2D), lipid-rich debris (Fig. 3A), fibrous debris (Fig. 3B), calcified debris (Fig. 3C) or thrombotic debris (Fig. 3D). The area of filer membrane was quantified and $43.5 \%$ of the area was occupied with debris or thrombosis. Although the advantage of the filter device is continuation of blood flow during the procedure, blood flow is occasionally reduced due to plaque debris or thrombosis $(3,4,6)$. In case of no-flow phenomenon during stenting procedure, $88.5 \%$ of filter area was covered. Additionally, in three cases of slow-flow phenomenon, more than $50 \%$ of area was covered. Taken together, occupied area influenced blood flow reduction during stenting procedure. As shown in Fig. $2 \mathrm{H}$, thrombotic material or cell adhesion to the filter membrane emphasized the importance of antithrombotic agent to prevent this phenomenon.

Recent radiological development allows us to evaluate component of the carotid plaque preoperatively. For example, angiography shows irregularity or ulceration of the stenotic lesion. Hypoechoic lesion on ultrasound is considered as vulnerable plaque. CT angiography is feasible for detecting calcification. We have been 
characterizing carotid plaque using high-resolution MRI comparing with samples from carotid endarterectomy $(8,9)$. Recognition of the imaging features corresponding to the histopathologic constituents of carotid plaques associated with increased risk of distal embolization during endovascular intervention would be very useful before deciding on therapy options in individual cases. Since distal protection is not always guaranteed because of possible fatty shower embolism, carotid endarterectomy should be recommended for an unstable, lipid-rich plaque rather than stenting.

\section{Conclusion}

Carotid plaque debris which were captured at stenting were HE stained and observed under microscopy. This simple method allows us to better understand plaque debris and appearance of embolus protection filter.

\section{References}

1) Angelini A, Reimers B, Della Barbera M, Saccà S, Pasquetto G, Cernetti C, Valente M, Pascotto P, Thiene G. Cerebral protection during carotid artery stenting: collection and histopathologic analysis of embolized debris. Stroke. 2002;33:456-461.

2) Asakura F, Kawaguchi K, Sakaida H, Toma N, Matsushima S, Kuraishi K, Tanemura H, Miura Y, Maeda M, Taki W. Diffusion-weighted magnetic resonance imaging in 
carotid angioplasty and stenting with balloon embolic protection devices. Neuroradiology. 2006;48:100-112.

3) Casserly IP, Abou-Chebl A, Fathi RB, Lee DS, Saw J, Exaire JE, Kapadia SR, Bajzer CT, Yadav JS. Slow-flow phenomenon during carotid artery intervention with embolic protection devices: predictors and clinical outcome. J Am Coll Cardiol. 2005;46:1466-1472.

4) du Mesnil de Rochemont R, Schneider S, Yan B, Lehr A, Sitzer M, Berkefeld J. Diffusion-weighted MR imaging lesions after filter-protected stenting of high-grade symptomatic carotid artery stenoses. AJNR Am J Neuroradiol. 2006;27:1321-1325.

5) Hayashi K, Kitagawa N, Morikawa M. Observing the carotid debris aspirated during carotid stenting: technical note. Neurol Res. 2005;27:22-26.

6) Hendriks JM, Zindler JD, van der Lugt A, Pattynama PM, van Sambeek MR, Bosch JL, van Dijk LC. Embolic protection filters for carotid stenting: differences in flow obstruction depending on filter construction. J Endovasc Ther. 2006;13:47-50.

7) Hill MD, Morrish W, Soulez G, Nevelsteen A, Maleux G, Rogers C, Hauptmann KE, Bonafé A, Beyar R, Gruberg L, Schofer J; MAVErlC International Investigators. Multicenter evaluation of a self-expanding carotid stent system with distal protection in 
the treatment of carotid stenosis. AJNR Am J Neuroradiol. 2006;27:759-765.

8) Honda M, Kitagawa N, Tsutsumi K, Nagata I, Morikawa M, Hayashi T. High-resolution magnetic resonance imaging for detection of carotid plaques. Neurosurgery 2006;58:338-46.

9) Kawahara I, Morikawa M, Honda M, Kitagawa N, Tsutsumi K, Nagata I, Hayashi T, Koji T.High-resolution magnetic resonance imaging using gadolinium-based contrast agent for atherosclerotic carotid plaque. Surg Neurol. 2007;68:60-66.

10) Kim SJ, Roh HG, Jeon P, Kim KH, Lee KH, Byun HS, Moon WJ, Kim GM, Kim YW, Kim DI. Cerebral ischemia detected with diffusion-weighted MR imaging after protected carotid artery stenting: comparison of distal balloon and filter device. Korean J Radiol. 2007;8:276-285.

11) Maleux G, Demaerel P, Verbeken E, Daenens K, Heye S, Van Sonhoven F, Nevelsteen A, Wilms G. Cerebral ischemia after filter-protected carotid artery stenting is common and cannot be predicted by the presence of substantial amount of debris captured by the filter device. AJNR Am J Neuroradiol. 2006;27:1830-1833.

12) Powell RJ, Alessi C, Nolan B, Rzucidlo E, Fillinger M, Walsh D, Wyers M, Zwolak R, Cronenwett JL. Comparison of embolization protection device-specific technical 
difficulties during carotid artery stenting. J Vasc Surg. 2006;44:56-61.

13) Roffi M, Yadav JS: Carotid stenting.Circulation. 2006;114:e1-4.

14) Rogers C, Huynh R, Seifert PA, Chevalier B, Schofer J, Edelman ER, Toegel G, Kuchela A, Woupio A, Kuntz RE, Macon ND. Embolic protection with filtering or occlusion balloons during saphenous vein graft stenting retrieves identical volumes and sizes of particulate debris. Circulation. 2004;109:1735-1740.

15) Schönholz CJ, Uflacker R, Mendaro E, Parodi JC, Guimaraes M, Hannegan C, Selby B: Techniques for carotid artery stenting under cerebral protection. J Cardiovasc Surg (Torino). 2005;46:201-217.

16) Veselka J, Cerná D, Zimolová P, Blasko P, Fiedler J, Hájek P, Maly M, Zemánek D, Duchonová R. Thirty-day outcomes of direct carotid artery stenting with cerebral protection in high-risk patients. Circ J. 2007;71:1468-1472.

17) White CJ, Iyer SS, Hopkins LN, Katzen BT, Russell ME; BEACH Trial Investigators. Carotid stenting with distal protection in high surgical risk patients: the BEACH trial 30 day results. Catheter Cardiovasc Interv. 2006;67:503-51.

18) Yadav JS, Wholey MH, Kuntz RE, Fayad P, Katzen BT, Mishkel GJ, Bajwa TK, 
Whitlow P, Strickman NE, Jaff MR, Popma JJ, Snead DB, Cutlip DE, Firth BG, Ouriel K; Stenting and Angioplasty with Protection in Patients at High Risk for Endarterectomy Investigators: Protected carotid-artery stenting versus endarterectomy in high-risk patients. N Engl J Med. 2004;351:1493-1501. 


\section{Figure legends}

\section{Fig. 1 Debris observation procedure}
A: embolus protection filter
B: Removed filter membrane

\section{Fig. 2 Case 9}

A: Lateral view of the angiography showed high-grade stenosis at the origin of the left internal carotid artery.

B: CT angiography demonstrated high density lesion at the stenosis, indicating severe calcification.

C: The plaque was demonstrated as isointensity with high-resolusion T1 weighted MRI (arrow).

D: Angiography after embolus protection filter and stent navigation.

E: Angiography after balloon angioplasty and capturing the filter showed satisfactory widening of the stenosis.

F: Microscopical observation of the embolus protection filter.

G: Organized debris

H: Blood cells adhesion to the membrane.

The pore $(100 \mu \mathrm{m})$ allows for quantitative determination of the debris size.

Original magnification X 25 (F), X 100 (G), X 200 (H). 
Fig. 3 Debris analysis
A: Lipid rich debris
B: Fibrous debris
C: Calcified debris
D: Thrombotic debris

Original magnification X 100 . 
Fig. 1

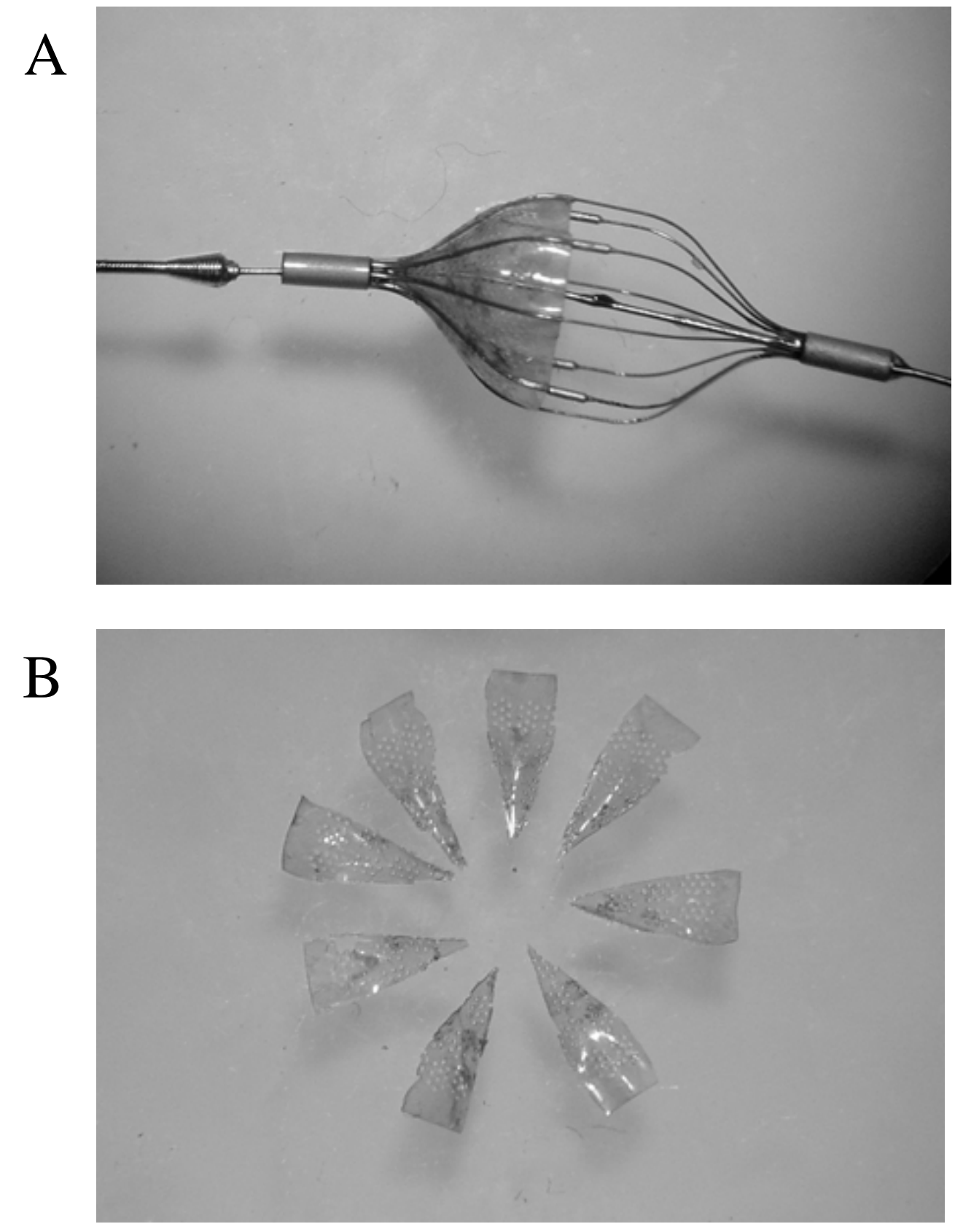


Fig. 2

A
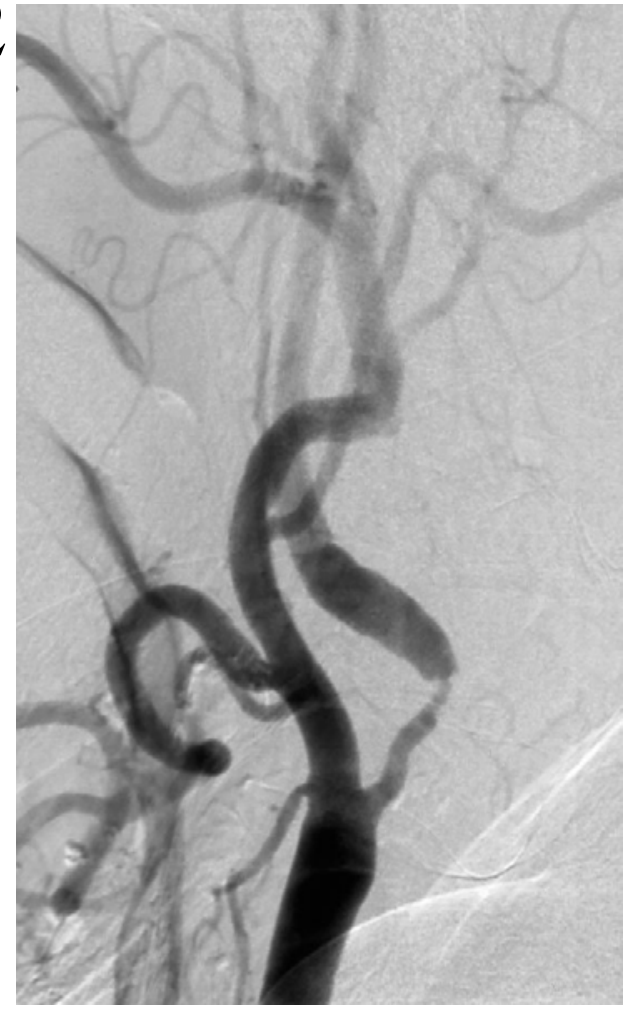

B
D

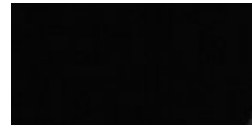

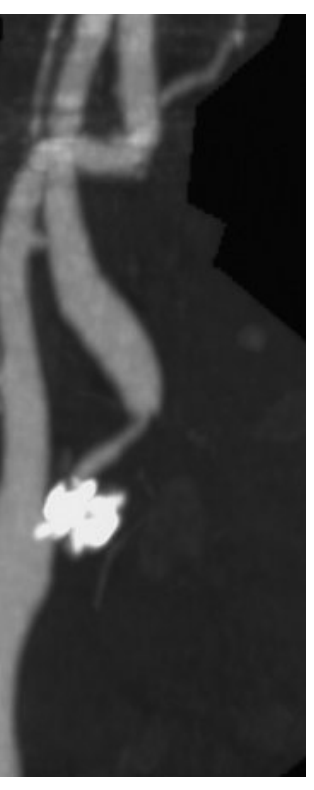

C

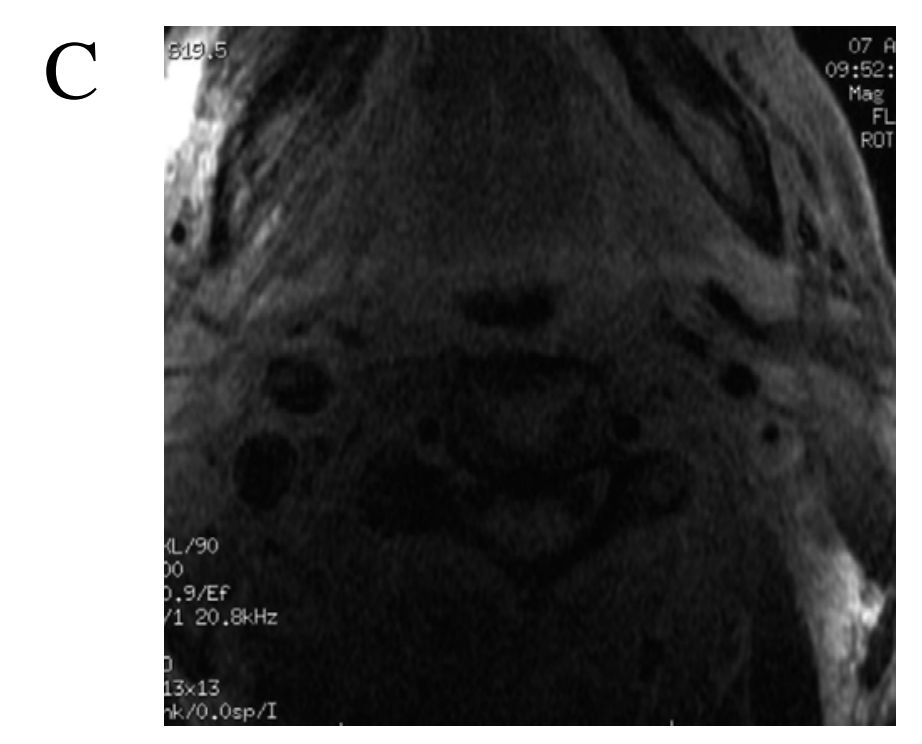

E

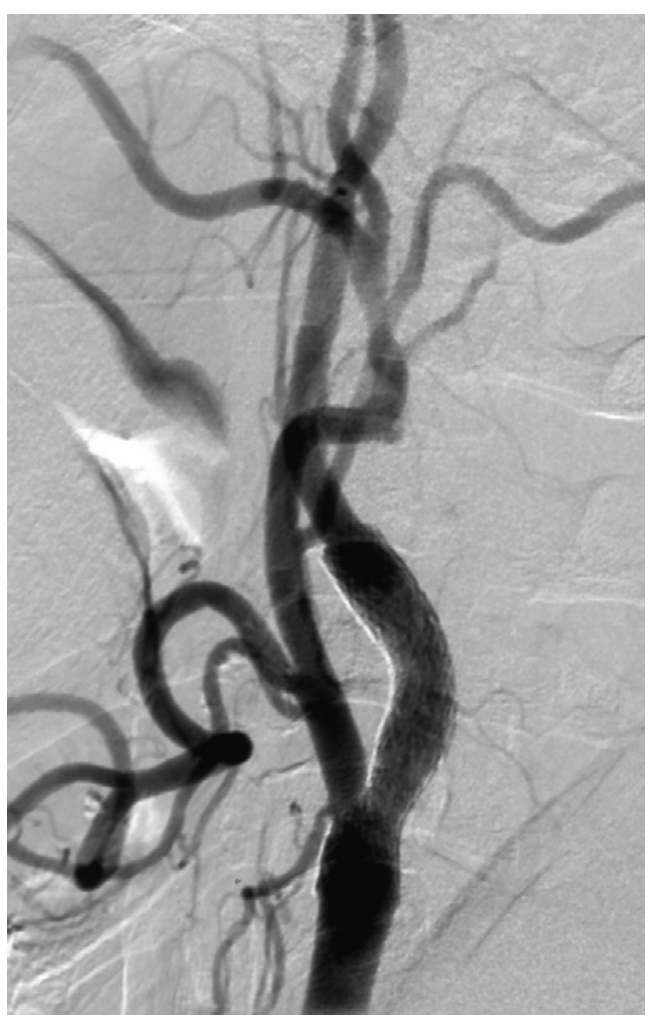


Fig. 2

F

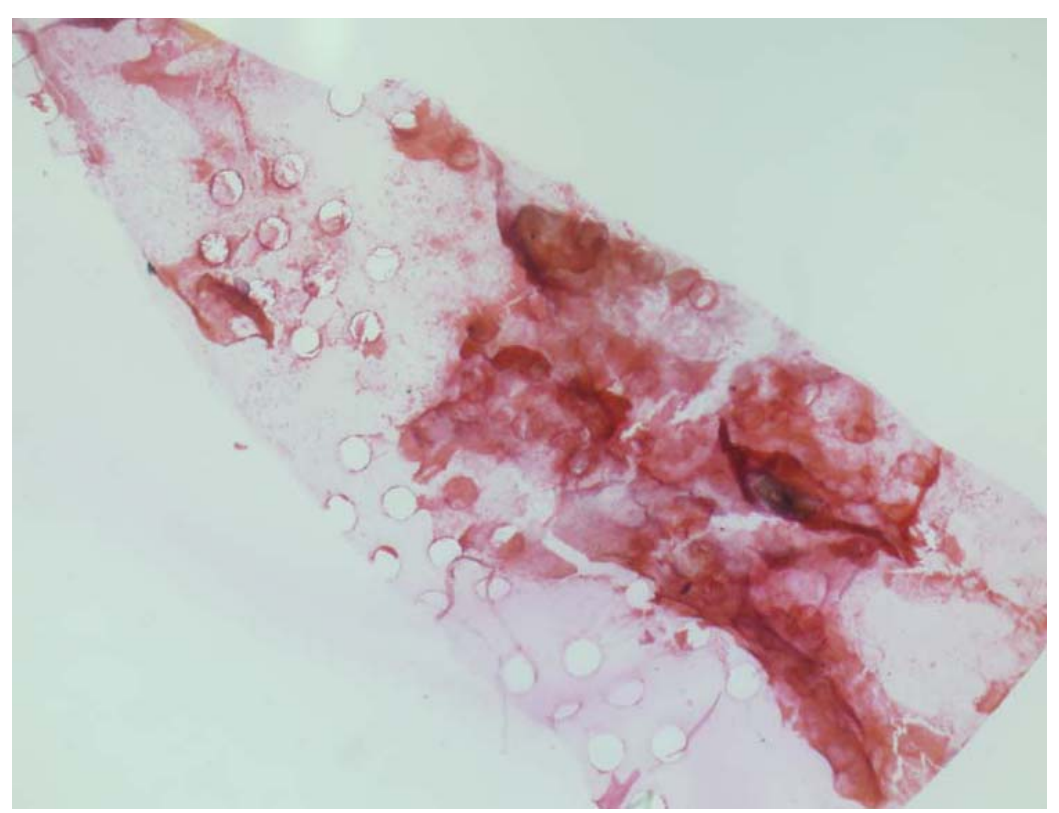

G

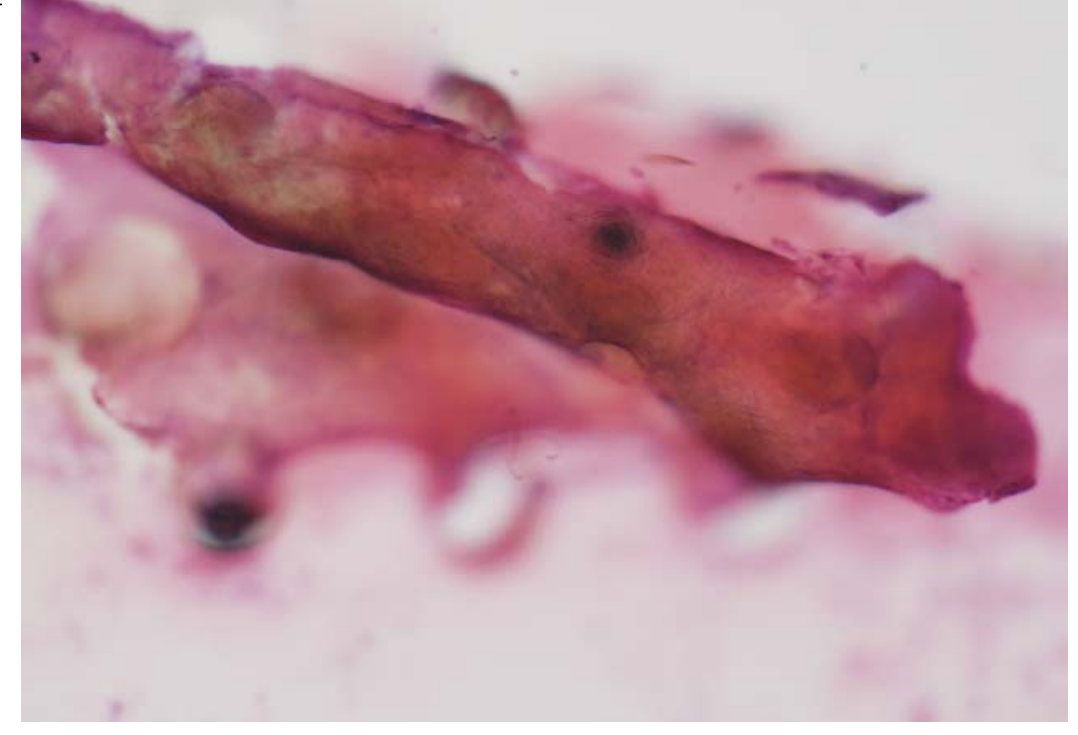

H

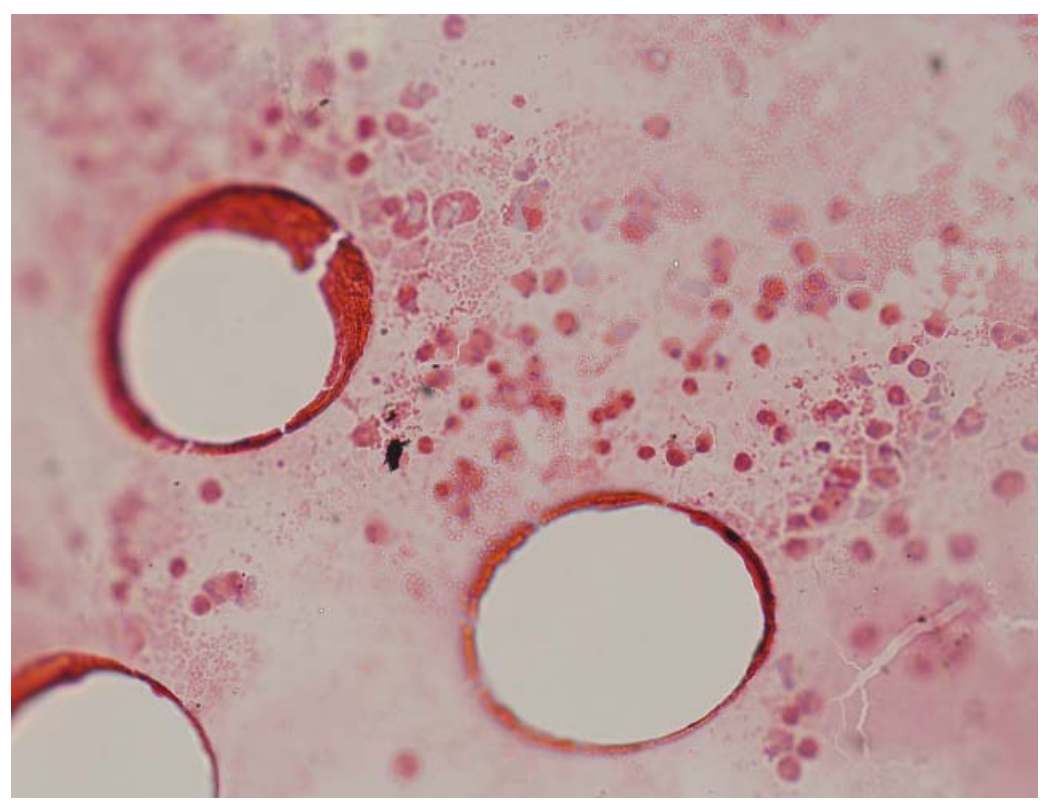


Fig. 3

A

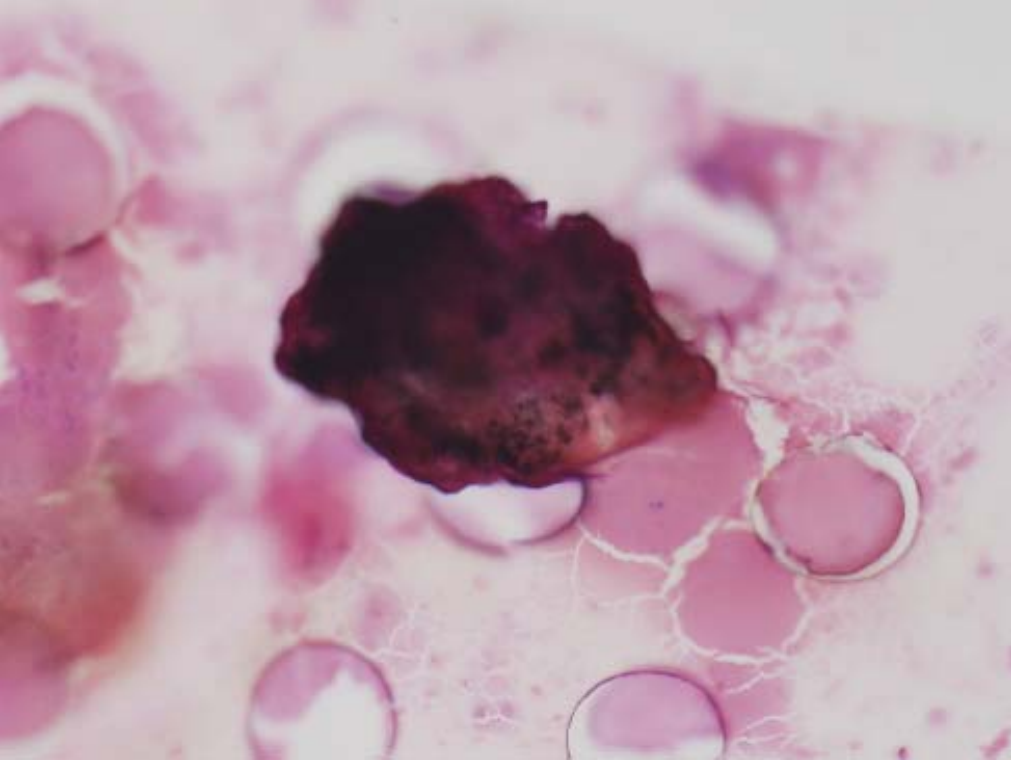

B

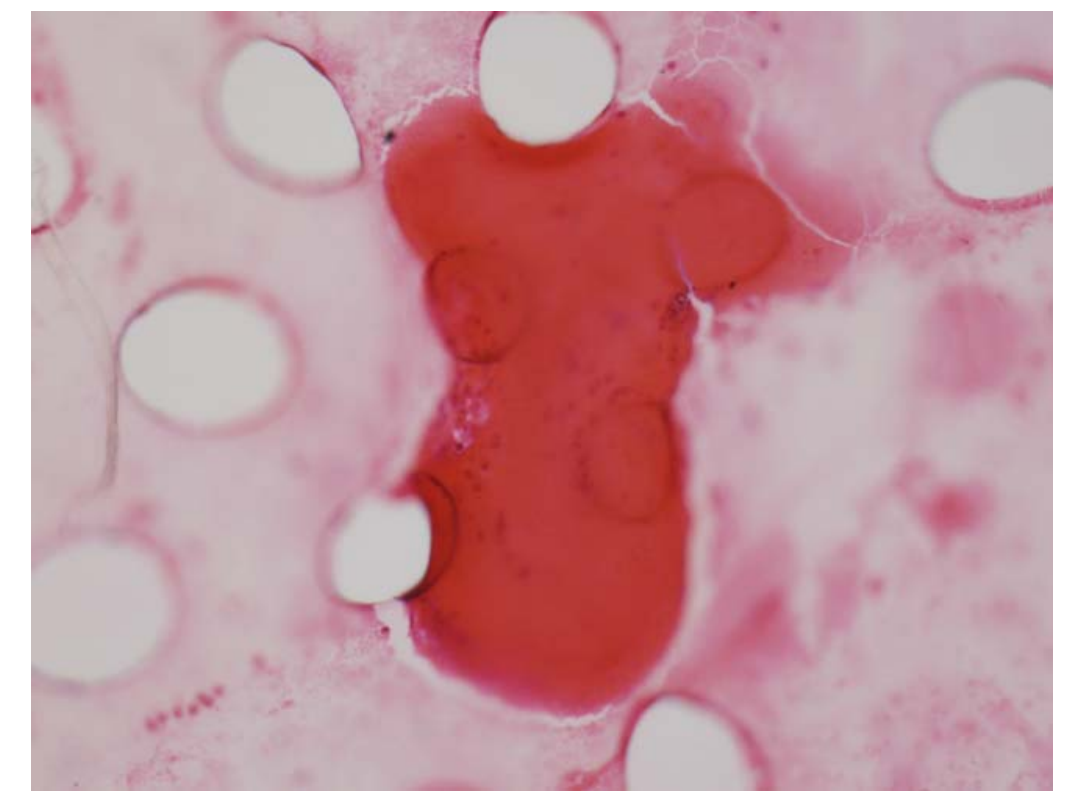

C

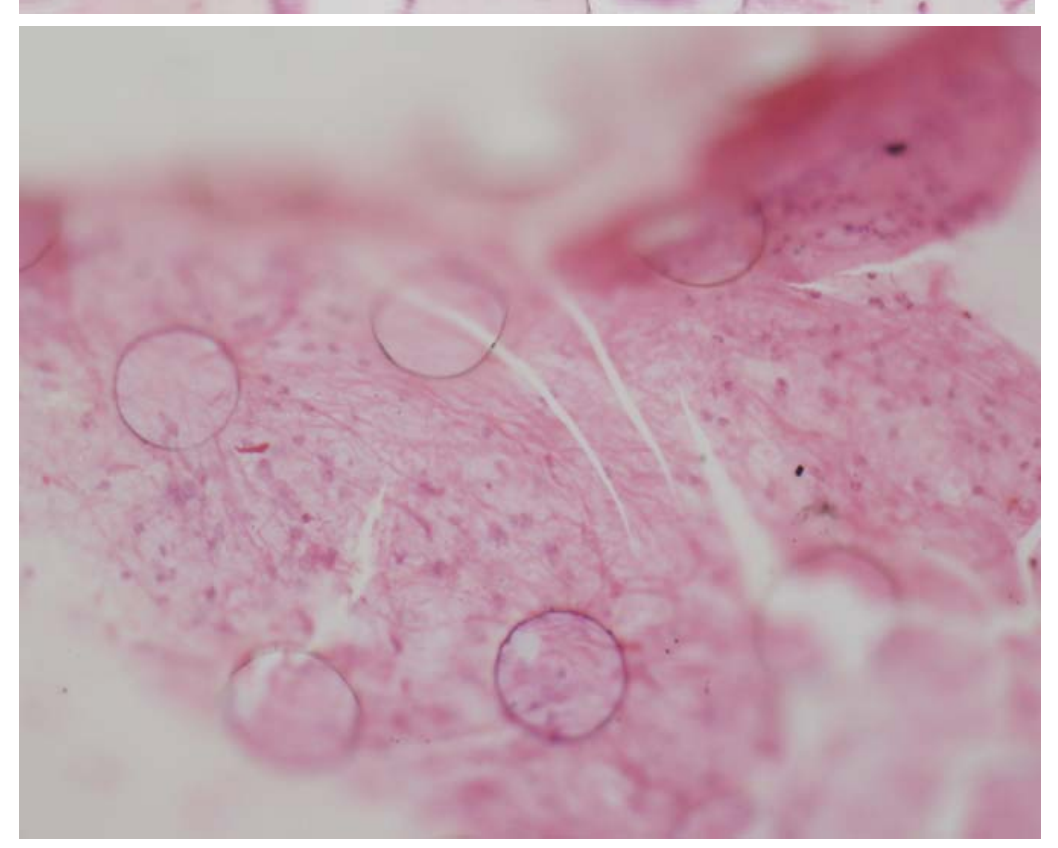

D

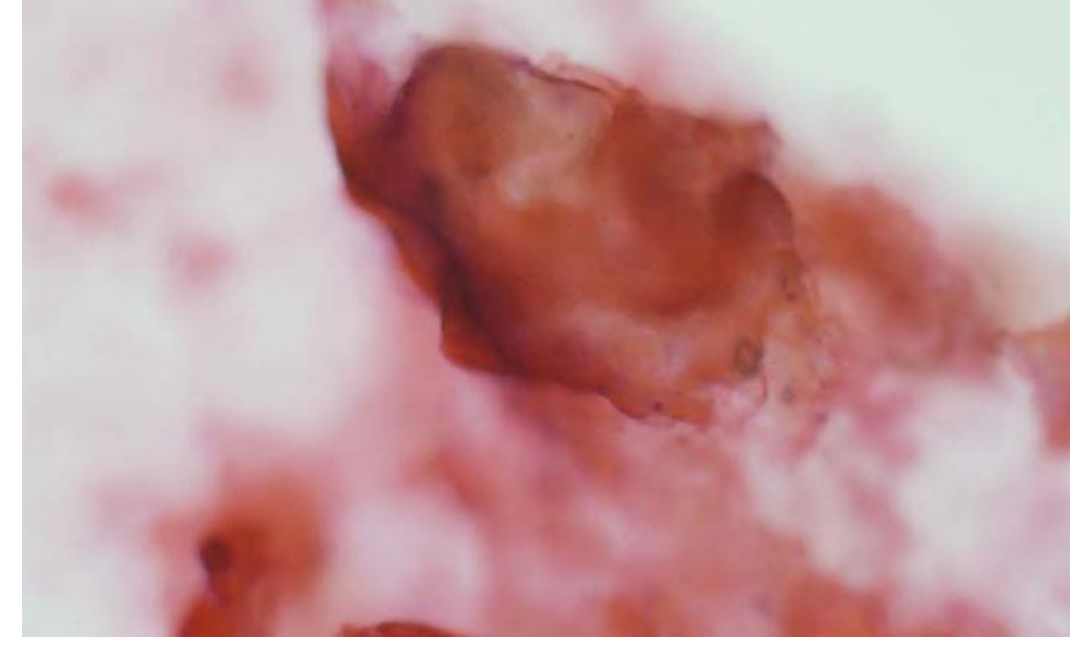

